\title{
Utility of a Multilevel Modeling Approach to Investigate Differences in Isolation Frequency of Fusarium culmorum in Agricultural Soil Across the Inland Pacific Northwest
}

\author{
Andrew Robinson, Dojin Ryu, and Hyun Jung Lee ${ }^{\dagger}$ \\ School of Food Science, University of Idaho, Moscow, ID 83844-2312 \\ Accepted for publication 11 January 2019.
}

\begin{abstract}
The plant pathogen Fusarium culmorum represents an inoculum source capable of contaminating grains with deoxynivalenol in the Inland Northwest region of the United States. A multilevel modeling approach utilizing varying intercepts for different sampling quadrats, fields, and iterations in the dataset was performed to characterize differences in isolation frequency of F. culmorum collected during a 2-year soil survey. Differences in the isolation frequency of $F$. culmorum varied the most by sampled field followed by quadrat and iteration, respectively. Higher relative elevation within the sampling region of a field limited the amount of F. culmorum recovered. The
\end{abstract}

ABSTRACT

Fusarium culmorum (Wm.G. Sm.) Sacc. 1895 (Ascomycetes, Hypocreales) is a causal agent of Fusarium head blight (FHB) and Fusarium root rot (FRR) of cereals and limits the production of winter wheat (Triticum aestivum L.) across the Inland Northwest (INW) region of the United States (Poole et al. 2013). Mycotoxin production in the form of trichothecenes (e.g., deoxynivalenol [DON] and nivalenol) is a common feature among F. culmorum isolates collected worldwide (Bakan et al. 2002; Gang et al. 1998; Jennings et al. 2004; Laraba et al. 2017; Quarta et al. 2005; Yekkour et al. 2015). Infection of grains by F. culmorum is of concern for both agriculture and food safety, because yield reduction is highly correlated with DON content in grains (Snijders and Perkowski 1990).

The INW currently produces winter wheat with some of the lowest levels of average DON in the continental United States (Bianchini et al. 2015). The primary causal agent of FHB, Fusarium graminearum, is rarely present in this region, because the primary inoculum source for $F$. graminearum is corn residue rather than wheat or its stubbles (Dill-Macky and Jones 2000). It was reported that only one isolate was recovered of 831 Fusarium spp. isolated from 2,250 wheat crowns collected across eastern Washington and Oregon (Smiley and Patterson 1996). The Mediterranean climate regime of the INW is not favorable for the development of corn or FHB, because most annual rainfall only occurs from October to March (Schillinger et al. 2010). Although wheat is most susceptible to FHB during midanthesis (Lacey et al. 1999), the dry conditions in the INW during anthesis limit fungal infection and DON production

†Corresponding author: H. J. Lee; hlee@uidaho.edu

Funding: This work is supported by U.S. Department of Agriculture (USDA) National Institute of Food and Agriculture Hatch project IDA01601.

*The $\boldsymbol{e}$-Xtra logo stands for "electronic extra" and indicates that three supplementary figures and three supplementary tables are published online.

The author(s) declare no conflict of interest.

(C) 2019 The American Phytopathological Society effect of annual climate variables was investigated using combinations of single-variable and multivariable model equations with linear and polynomial terms. The same data analysis approach was applied to an external dataset of F. culmorum isolation frequencies in grains from fields across eastern Australia. These results represent a case study for investigating variability within datasets containing overdispersed fungal counts and incorporating climate summaries as predictor variables.

Keywords: ecology, epidemiology, mycotoxins, postharvest pathology in grains, which are dependent on high relative humidity during flowering (Beyer et al. 2005; De Wolf et al. 2003).

However, the climate of the INW is forecasted to change in the upcoming decades (Abatzoglou et al. 2013), with warmer winters, springs, and summers in addition to wetter springs and drier summers predicted by 2070 (Pan et al. 2017). Warmer winters may allow $F$. culmorum populations in soil to increase and cause increased infection pressure during the following growing season (Lukas et al. 2014). In addition, hot and dry conditions during summer can initiate plant water stress, which predisposes crops to F. culmorum infections (Papendick and Cook 1974). Warmer and wetter springs are a concern, because both the incidence of FHB and the concentration of DON increase with increasing periods of wetness and temperature (Cowger et al. 2009; Xu et al. 2007). Flowering typically occurs in mid-May to late May for winter wheat grown in the INW, but rising temperatures may shift flowering dates earlier in the year ( $\mathrm{Hu}$ et al. 2005). To address the food safety concerns of DON contamination in grains from the INW under climate change, the current inoculum source needs to be quantified and related to climatic factors.

Quantifying the prevalence of $F$. culmorum of total Fusarium spp. in agricultural soil is difficult because of the high degree of variability accompanied by the methods of enumeration. Population densities of soil Fusarium spp. can vary widely within sampling quadrats as small as $10 \times 10 \mathrm{~cm}$ (Rodriguez-Molina et al. 2000). In addition, population densities of $F$. culmorum are known to fluctuate seasonally (Bateman and Murray 2001). Fortunately, the regional distribution of $F$. culmorum prevalence is more relevant to the issue of climate change in the INW and has been related to local climate at that scale (Poole et al. 2013).

Isolation frequency of $F$. culmorum from infected wheat and barley roots across 13 southern Idaho counties was higher than in counties with greater annual precipitation (Strausbaugh et al. 2004). Isolation frequency of $F$. culmorum in crops is related to their soil populations, because the population density of the fungus in soil is proportional to FRR disease severity (Cook 1968). The population density of $F$. culmorum recovered from field soil was greater in Pullman, Washington compared with Ritzville, Washington, where the climate is hotter and drier (Cook and Bruehl 1968). The longevity of 
chlamydospores of F. culmorum in artificially inoculated soil samples that were buried in Pullman, Washington was greater compared with in Lind, Washington (Inglis and Cook 1986; Sitton and Cook 1981). Lind, Washington receives less annual rainfall than Pullman, Washington while also having warmer summers. An extensive survey across the INW combined with factor analysis and logistic regression determined that greater annual precipitation increased the isolation frequency of $F$. culmorum of total Fusarium spp. from winter wheat stubble (Poole et al. 2013). In general, F. culmorum was found more frequently in areas of the INW with higher elevations and moisture and with cooler temperatures.

Research into the regional distribution of Fusarium spp. pathogenic to grains has also been extensively surveyed across Australia. The range and mean of 16 different climate parameters were calculated for the distribution of F. culmorum in cereals across Australia using accession records from multiple lyophilized culture collections and the BIOCLIM version 2.0 program (Backhouse and Burgess 2002). A survey of stem bases collected from crops across the eastern Australian grain belt confirmed that $F$. culmorum was common and widespread in cooler and wetter areas of Victoria and South Australia (Backhouse et al. 2004). Isolation frequency of F. culmorum correlated best with November rainfall measured from the nearest meteorological station.

The objective of this work was to evaluate the relationship between climatic variables and the prevalence of $F$. culmorum using isolation records from a study to collect potentially toxigenic isolates of soil Fusarium spp. Because isolation frequency varies by time and location, multiple fields were sampled seasonally for 2 years. Although the culture collection will be utilized for food safety research, this manuscript attempts to characterize differences in isolation frequency of a fungal plant pathogen in soil based on various experimental clusters within the dataset.

Inferences gained can provide the scaffolding to guide the construction of more complex models in the future for use with climate change ensembles. The data analysis approach herein provides a case study for plant pathologists who also work with count data of fungal plant pathogens to better investigate how experimental units within their datasets vary. Another applied approach is presented using an external dataset from Backhouse et al. (2004) to compare estimates for parameters using similar climatic variables.

\section{MATERIALS AND METHODS}

Soil sampling and weather monitoring. Field locations were selected based on grower cooperation with the help of extension specialists from both the University of Idaho and Washington State University. All fields were within 50 miles of Moscow, Idaho. The survey consisted of three separate fields each within the annual crop, transitional, and grain-fallow agroecological classes delineated by Douglas et al. (1992), giving a total of nine fields.

The sampling region within each field consisted of nine quadrats 1 acre $\left(4,047 \mathrm{~m}^{2}\right)$ in size arranged in a $3 \times 3$ grid pattern. The positions of all 16 vertices of the sampling grid were calculated using an offset of $63.62 \mathrm{~m}$ and converting the distance to decimal degrees for each field. Elevation in meters for each vertex was estimated using FreeMapTools (https://www.freemaptools.com/ elevation-finder.htm). The elevation of each sampling quadrat was the average of four vertices. Maps of sampling regions were created using the Google Maps API interface and uploaded onto a smartphone (Samsung Galaxy S7) as a georeference while sampling.

During each sampling iteration, six subsamples were taken from each quadrat of a field using a systematic unaligned grid methodology (Franzen and Cihacek 1998). A subsample was defined as a soil core $10 \mathrm{~cm}$ in depth taken using a 7/8-inch soil probe (AMS). Subsamples were collected from random locations within each quadrat, and the global positioning system (GPS) accuracy radius was always completely within a quadrat during sample collection. Subsamples for each quadrat were pooled into a labeled plastic bag for transport. After they were in the laboratory, soil samples were dried in a biosafety cabinet in weighing dishes for $48 \mathrm{~h}$ before processing. Soil samples were ground with a pestle and mortar to pass a 2-mm sieve and mixed thoroughly before dilution. Soil moisture was measured using a moisture meter (HB43-S; Mettler Toledo). Soil sampling occurred every 3 months from 11 June 2016 to 17 March 2018.

The primary inoculum capable of causing FHB within the INW is soilborne (Paulitz et al. 2002). Spatiotemporal spread of F. culmorum was not considered in this study, because the longterm survival of $F$. culmorum chlamydospores in soil is considered the reason that inoculum levels within a field remain constant despite crop rotations (Cook and Bruehl 1968; Windels et al. 1993). It was assumed that $F$. culmorum had a cosmopolitan distribution in soils across the INW and that environmental factors could be used to determine the relative amount present in a field (Poole et al. 2013; Smiley and Patterson 1996).

Site-specific weather data were collected using Climate Engine (https://clim-engine.appspot.com/). The GPS coordinates from the center of each field's sampling region were used as inputs for Climate Engine to collect daily weather data from the corresponding cell within a 4-km raster dataset (Abatzoglou 2013). Daily values for precipitation, maximum temperature, minimum temperature, and grass reference evapotranspiration were collected from 1 January 1980 to 31 December 2018. Grass reference evapotranspiration was calculated using the Penman-Montlieth equation (ASCE-EWRI 2005). Daily maximum and minimum temperatures were used to calculate growing degree-days (GDDs) with a base temperature of $0^{\circ} \mathrm{C}$. GDDs are used to describe the heat energy received by a crop over a given interval of time. Maximum and minimum temperatures were referenced against the base temperature before averaging (McMaster and Wilhelm 1997). For each year in the dataset $(n=38)$, the total sum of each variable was calculated for each field to produce an annual average.

Soil dilution plating. Ten grams of soil from each quadrat sampled was suspended in $100 \mathrm{ml}$ of sterile $0.05 \%$ water agar (WA) and mixed for 30 min using a wrist action shaker (Burrell Model 75). Additional dilutions were performed using additional $0.05 \%$ WA first to $1 \mathrm{~g} / 100 \mathrm{ml}$ followed by serial twofold dilutions up to 1 $\mathrm{g} / 800 \mathrm{ml}$. A 1-ml aliquot of each twofold dilution was plated onto Nash-Snyder media (Nash and Snyder 1962). The source of pentachloronitrobenzene was Blocker $4 \mathrm{~F}$ by Amvac Chemical Corporation. Soil dilution plating was performed in duplicate for each quadrat. Plates were incubated in a greenhouse by placing them adjacent to a north-facing window for sunlight for 5 days. Colonies that exhibited unrestricted growth were assumed to be Fusarium species (Nash and Snyder 1962).

After incubation, the soil dilution for each replicate that produced $\sim 10$ to 25 colonies per plate was selected for subculturing. This range is based on 10 colonies being the minimum necessary to ensure sampling adequate species diversity, and plates with above 25 colonies were typically overcrowded (Sangalang et al. 1995). Colonies of interest were labeled and transferred to homemade potato dextrose agar (PDA) (Nelson et al. 1983). To conserve space and resources when handling thousands of isolates, $1 \mathrm{ml}$ of homemade PDA was dispensed into reservoirs of 24-well plates (Primaria), with each fungal isolate occupying a single well. After 3 days, only red-pigmented colonies were transferred to carnation leaf agar and identified further, because they represented all species known to be pathogenic to cereals and also, potential tricothecene producers (Backhouse et al. 2004). After incubation for 2 weeks, isolates were identified as $F$. culmorum using morphological criteria (Leslie and Summerell 2008; Nelson et al. 1983; Samson et al. 2004). The isolation frequency of $F$. culmorum of total soil Fusarium spp. was first calculated by summing both replicates for a 
given quadrat. Isolation frequency was also calculated by summing all replicates from a field after a single sampling iteration.

Data analysis approach. The dataset contained counts of $F$. culmorum colonies $(c)$ from field $(i)$ at quadrat $(j)$ during sampling iteration $(k)$ of total soil Fusarium spp. (n). "Sampling iteration" was defined as every unique sampling point for nine fields across eight seasons $(n=72)$, letting each vary independently, because there was no consistent temporal trend across consecutive sampling periods. The reported outcome is a binary result of the number of identified $F$. culmorum isolates of all Fusarium colonies observed during soil dilution plating. Determining the proportion of a plant pathogen of interest within a specific fungal genus is a familiar research outcome in plant pathology. The proportion of F. culmorum in the soil of total soil Fusarium spp. $\left(p_{i j k}\right)$ was modeled using a binomial likelihood distribution, where $c_{i j k}$ is approximately $\operatorname{Binomial}\left(n_{i j k}, p_{i j k}\right)$. The term $c_{i j k}$ represents the number of $F$. culmorum colonies for the $i$ th field, $j$ th quadrat, and $k$ th iteration. The term $p_{i j k}$ represents the unobserved true proportion of F. culmorum, which will be estimated using the dataset. The logit link, where $\operatorname{logit}(p)=\ln (p /(1-p))$, was used to build a regression model for $p_{i j k}$ using varying intercepts for $i, j$, and $k$. The equation used for determining the unique log odds given the dataset was

$$
\operatorname{logit}\left(p_{i j k}\right)=a+a_{i}+a_{j}+a_{k}
$$

where $a_{i}, a_{j}$, and $a_{k}$ represent the additive effects of the $i$ th field, $j$ th quadrat, and $k$ th iteration, respectively, which modify the overall population parameter $a$. The prior distribution for $a$ was $\operatorname{Normal}(0$, 100 ), which is weakly regularizing. A regularizing prior is used to both minimize overfitting and allow the Markov chains to sample properly. Prior distribution for offsets was $\operatorname{Normal}\left(0, \sigma^{2}\right)$.The prior distribution for the variance parameters $\sigma_{i}^{2}, \sigma_{j}^{2}$, and $\sigma_{k}^{2}$ was Half Cauchy $(0,1)$ for offsets $i, j$, and $k$. A Half Cauchy prior was used for the variance estimates as found in McElreath (2016). The Half Cauchy distribution is approximately uniform in the tail, and it is considered "weakly informative" (Gelman 2006). Increasing the prior for the variance parameters by a factor of 10 did not change the posterior distribution of the additive effect parameters (Supplementary Fig. S1).

This approach accounted for overdispersion in the dataset by assigning a unique intercept for all unique fields $(n=9)$, quadrats ( $n=81)$, and sampling iterations and allowing them to vary independently. Definitions of "sampling iteration" based temporal sequence $(n=8)$ or season $(n=4)$ were also analyzed. The posterior probabilities for $p_{i j k}$ were estimated using Bayesian analysis through the rethinking package in $\mathrm{R}$ (McElreath 2016). The rethinking package in $\mathrm{R}$ converts model specifications into a format that can be utilized in Stan, which is a probabilistic programming language (Carpenter et al. 2017). Stan uses the Hamiltonian Monte Carlo algorithm to sample from a target posterior distribution, and an introduction can be found in Betancourt (2017).

Parameters for the Markov chain included a warmup of 1,000 iterations followed by 5,000 sampling iterations using four chains distributed across four cores. Parameters for the Markov chains remained constant for all models presented. The output was checked for convergence using the Gelman-Rubin statistic $\hat{R}$ (Gelman and Rubin 1992). Markov chains were assumed to have converged when the value of $\hat{R}$ was 1.00 . The model output consists of a distribution of 20,000 parameter estimates, the frequency of which corresponds to their relative plausibility given the dataset and model formula. Posterior distributions for parameters are summarized by either mean \pm standard deviation or the $95 \%$ highest posterior density interval (HDPI). An HDPI is the narrowest range of values containing a specified probability mass, which in this study, was $95 \%$. Although there are many possible intervals with the same mass, the HDPI answers which interval is the densest. The resulting range utilizes parameter values with the highest posterior probability while also being the narrowest (McElreath 2016). A 95\% HDPI that excluded zero was used as justification for a parameter value being predominantly positive or negative.

Adding annual climate summaries as predictor variables. The effect of a climate variable $x$ was first modeled as a slope $b$, where $x$ was average annual precipitation, evapotranspiration, or GDD calculated using the historical daily dataset from 1980 to 2018. Annual averages were used as a proxy for field differences based on climatic summaries. Shorter timescales were not analyzed owing to the stochastic changes within fields across sampling iterations. The updated link equation becomes

$$
\operatorname{logit}\left(p_{i j k}\right)=a+a_{i}+a_{j}+a_{k}+b x
$$

Climate variables were standardized to mean of zero with standard deviation of one before analysis. The prior distribution for $b$ was $\operatorname{Normal}(0,10)$, and all of the following equations utilize the same prior for all parameters associated with climate variables. This approach gives unique fields, quadrats, and sampling iterations their own intercept and assumes a fixed linear relationship between the climate parameter being analyzed and the log odds of a Fusarium colony isolated from soil being $F$. culmorum. Polynomial regression using a quadratic parameter was also investigated. For a single climate variable $x$, the updated link equation becomes

$$
\operatorname{logit}\left(p_{i j k}\right)=a+a_{i}+a_{j}+a_{k}+b_{1} x+b_{2} x^{2}
$$

This approach gives unique fields, quadrats, and sampling iterations their own intercept and assumes a nonlinear relationship between the climate parameter being analyzed and the log odds of a Fusarium colony isolated from soil being F. culmorum.

Multivariable models using two climate variables were also investigated. For climate variables $x$ and $y$ assuming a multivariable linear relationship, the updated link equation becomes

$$
\operatorname{logit}\left(p_{i j k}\right)=a+a_{i}+a_{j}+a_{k}+b_{1} x+b_{2} y+b_{3} x y
$$

All combinations of climate variables $x$ and $y$ were tested with and without the interaction term. For climate variables $x$ and $y$ assuming a multivariable quadratic relationship, the updated link equation becomes

$$
\operatorname{logit}\left(p_{i j k}\right)=a+a_{i}+a_{j}+a_{k}+b_{1} x+b_{2} y+b_{3} x y+b_{4} x^{2}+b_{5} y^{2}
$$

Generalization of methodology to previous literature. The original dataset used in Backhouse et al. (2004) was generously provided by D. Backhouse. Annual precipitation and GDD were calculated using the nearest meteorological station to a field that was available from the Australian Bureau of Meteorology at the time of publication (D. Backhouse, personal communication). The dataset consists of F. culmorum counts (c) of total Fusarium spp. in grains $(n)$ collected from 163 fields. The same modeling equations as those used in this study were used with the Australian dataset without $a_{j}$ or $a_{k}$, because only the parameters for each $i$ th field were available. Climate variables were standardized to mean of zero with standard deviation of one before analysis, and posterior distributions of parameters were compared with this study.

Evaluation of model predictions. Model output using equations 2, 3, 4, and 5 contained 20,000 values for each parameter with a relative frequency proportional to relative plausibility given the dataset used. The distribution of each parameter value is based 
on the uncertainty in the dataset on which the model equation was conditioned. Uncertainty is propagated forward into model predictions by using the same equation used during model fitting and calculating the value of the linear model using samples from the posterior distribution. Model predictions were generated by first simulating a new varying intercept using the posterior distributions of $\sigma$ for field, quadrat, and iteration from the model being evaluated. The simulated intercept was then used with the posterior distribution of the effect parameters for annual climate variables to simulate predictions. The effect of the climate variables based on the model equation is visualized by the trend of the simulated intercept. By simulating and plotting multiple intercepts, the variation in proportions of $F$. culmorum owing to differences in fields, quadrats, and sampling iterations can be visualized. When evaluating multivariable models using equations 4 and 5 , the climate variable $y$ was set to the average when simulating predictions for a climate variable $x$.

All data and R scripts to reproduce the analyses shown here are deposited publicly on GitHub (https://github.com/nosnibor27/ PHYTO).

\section{RESULTS}

Frequency of isolation records. A total of 20,675 soil Fusarium spp. were collected during 2 years of sampling and yielded 2,293 isolates of $F$. culmorum. The number of $F$. culmorum isolates of total soil Fusarium spp. collected from 1-acre quadrats across nine fields and eight seasons is presented in Supplementary Table $\mathrm{S} 1$. The proportion of $F$. culmorum ranged from 0 to $85 \%$ of all soil Fusarium spp. within a 1-acre quadrat. The total number of F. culmorum isolates collected from a field during each sampling iteration is presented in Table 1. The resulting proportion is the average of all nine quadrats, but reporting proportions in this manner neglects the variability across field quadrats. In general, isolation frequency of $F$. culmorum within a field was highest in the winter and spring and lowest in the summer and fall. Surveys of F. culmorum conducted during harvest between July and August coincide with the period of the year when soil populations are the lowest, which may lead to biased inferences.

Total proportion data from both this study and Backhouse et al. (2004) are shown in Figure 1. The prevalence of F. culmorum in soil across the INW is much greater than in wheat across eastern Australia. F. culmorum was not recovered from soil samples in 244 of 648 cases in this study, and it was not recovered from 101 wheat samples of 163 cases in the dataset provided by Backhouse et al. (2004).

Posterior distributions of cluster offsets. Bayesian analysis was used to assess the variability in the isolation frequency of F. culmorum in soil based on sampling field, quadrat, and sampling iteration by assigning a unique intercept for each index across each cluster. The mean \pm standard deviation of the posterior distribution for $a$, the population average, was $-6.37 \pm 0.58$ using equation 1 . Units are in log odds, and therefore, the average percentage of a soil Fusarium spp. being F. culmorum given the data is $0.17 \%$ for the INW.

The means \pm standard deviations of the posterior distributions using equation 1 for $\sigma$ were $1.64 \pm 0.49,0.92 \pm 0.1$, and $0.63 \pm 0.08$ for field, quadrat, and sampling iteration, respectively. These values are conditional on the dataset used and show that isolation frequency of F. culmorum in soil varies the most by field followed by quadrat and sampling iteration. Tabulated summaries of marginal posterior distributions for sampling iteration and quadrat are presented in Supplementary Tables S2 and S3, respectively. The means \pm standard deviations of the posterior distributions for $\sigma_{k}$ for different interpretations of sampling iteration were $0.43 \pm 0.14$ and $0.48 \pm$ 0.32 for temporal sequence $(n=8)$ and season $(n=4)$, respectively. Posterior distributions for $\sigma_{k}$ using different interpretations of sampling iteration are visualized in Supplementary Figure S2.

The quality of model fit using equation 1 is visualized in Figure 2 by simulating 100 counts of $F$. culmorum from the posterior
TABLE 1. Seasonal differences in total field isolation frequency of Fusarium culmorum of soil Fusarium spp. in agricultural soil across the Inland Northwest

\begin{tabular}{|c|c|c|c|c|}
\hline Date & Field & $\mathrm{C}^{\mathrm{a}}$ & $\mathrm{T}^{\mathrm{b}}$ & Percentage \\
\hline 11 June 2016 & 1 & 26 & 339 & 8 \\
\hline 11 June 2016 & 2 & 13 & 243 & 5 \\
\hline 11 June 2016 & 3 & 32 & 360 & 9 \\
\hline 18 June 2016 & 4 & 22 & 281 & 8 \\
\hline 18 June 2016 & 5 & 40 & 243 & 16 \\
\hline 18 June 2016 & 6 & 7 & 317 & 2 \\
\hline 25 June 2016 & 7 & 21 & 263 & 8 \\
\hline 25 June 2016 & 8 & 5 & 250 & 2 \\
\hline 25 June 2016 & 9 & 1 & 302 & 0 \\
\hline 3 September 2016 & 1 & 45 & 296 & 15 \\
\hline 3 September 2016 & 2 & 14 & 263 & 5 \\
\hline 3 September 2016 & 3 & 25 & 274 & 9 \\
\hline 10 September 2016 & 4 & 53 & 261 & 20 \\
\hline 10 September 2016 & 5 & 75 & 275 & 27 \\
\hline 10 September 2016 & 6 & 15 & 297 & 5 \\
\hline 17 September 2016 & 7 & 1 & 264 & 0 \\
\hline 17 September 2016 & 8 & 1 & 259 & 0 \\
\hline 17 September 2016 & 9 & 1 & 305 & 0 \\
\hline 3 December 2016 & 1 & 66 & 258 & 26 \\
\hline 3 December 2016 & 2 & 15 & 290 & 5 \\
\hline 3 December 2016 & 3 & 37 & 299 & 12 \\
\hline 10 December 2016 & 4 & 86 & 358 & 24 \\
\hline 10 December 2016 & 5 & 44 & 298 & 15 \\
\hline 10 December 2016 & 6 & 49 & 374 & 13 \\
\hline 15 December 2016 & 7 & 4 & 327 & 1 \\
\hline 15 December 2016 & 8 & 2 & 322 & 1 \\
\hline 15 December 2016 & 9 & 0 & 273 & 0 \\
\hline 4 March 2017 & 1 & 37 & 303 & 12 \\
\hline 4 March 2017 & 2 & 36 & 368 & 10 \\
\hline 4 March 2017 & 3 & 81 & 288 & 28 \\
\hline 11 March 2017 & 4 & 87 & 290 & 30 \\
\hline 11 March 2017 & 5 & 54 & 269 & 20 \\
\hline 11 March 2017 & 6 & 19 & 303 & 6 \\
\hline 18 March 2017 & 7 & 1 & 275 & 0 \\
\hline 18 March 2017 & 8 & 4 & 290 & 1 \\
\hline 18 March 2017 & 9 & 1 & 284 & 0 \\
\hline 3 June 2017 & 1 & 35 & 274 & 13 \\
\hline 3 June 2017 & 2 & 7 & 289 & 2 \\
\hline 3 June 2017 & 3 & 60 & 284 & 21 \\
\hline 10 June 2017 & 4 & 83 & 298 & 28 \\
\hline 10 June 2017 & 5 & 70 & 290 & 24 \\
\hline 10 June 2017 & 6 & 19 & 272 & 7 \\
\hline 17 June 2017 & 7 & 25 & 330 & 8 \\
\hline 17 June 2017 & 8 & 4 & 309 & 1 \\
\hline 17 June 2017 & 9 & 2 & 337 & 1 \\
\hline 2 September 2017 & 1 & 17 & 289 & 6 \\
\hline 2 September 2017 & 2 & 13 & 279 & 5 \\
\hline 2 September 2017 & 3 & 38 & 276 & 14 \\
\hline 9 September 2017 & 4 & 38 & 299 & 13 \\
\hline 9 September 2017 & 5 & 48 & 239 & 20 \\
\hline 9 September 2017 & 6 & 1 & 237 & 0 \\
\hline 16 September 2017 & 7 & 1 & 219 & 0 \\
\hline 16 September 2017 & 8 & 1 & 219 & 0 \\
\hline 16 September 2017 & 9 & 1 & 250 & 0 \\
\hline 2 December 2017 & 1 & 73 & 249 & 29 \\
\hline 2 December 2017 & 2 & 18 & 296 & 6 \\
\hline 2 December 2017 & 3 & 104 & 359 & 29 \\
\hline 9 December 2017 & 4 & 120 & 280 & 43 \\
\hline 9 December 2017 & 5 & 67 & 283 & 24 \\
\hline 9 December 2017 & 6 & 8 & 327 & 2 \\
\hline 16 December 2017 & 7 & 6 & 237 & 3 \\
\hline 16 December 2017 & 8 & 2 & 262 & 1 \\
\hline 16 December 2017 & 9 & 0 & 282 & 0 \\
\hline 3 March 2018 & 1 & 93 & 315 & 30 \\
\hline 3 March 2018 & 2 & 16 & 313 & 5 \\
\hline 3 March 2018 & 3 & 81 & 322 & 25 \\
\hline 10 March 2018 & 4 & 124 & 254 & 49 \\
\hline 10 March 2018 & 5 & 87 & 288 & 30 \\
\hline 10 March 2018 & 6 & 6 & 329 & 2 \\
\hline 17 March 2018 & 7 & 1 & 230 & 0 \\
\hline 17 March 2018 & 8 & 1 & 253 & 0 \\
\hline 17 March 2018 & 9 & 3 & 245 & 1 \\
\hline
\end{tabular}

a Total number of $F$. culmorum isolates.

b Total number of total soil Fusarium spp. processed. 
distribution for each case in the dataset and comparing the result with the enumerated value. The predicted range of simulated counts does not always contain the enumerated value. This can be seen where the range of simulated counts is less than the empirical data for high counts $(>30)$ of $F$. culmorum within a specific quadrat. The posterior predictive check visualized in Figure 2 does not change based on different interpretations of sampling iteration (data not shown).
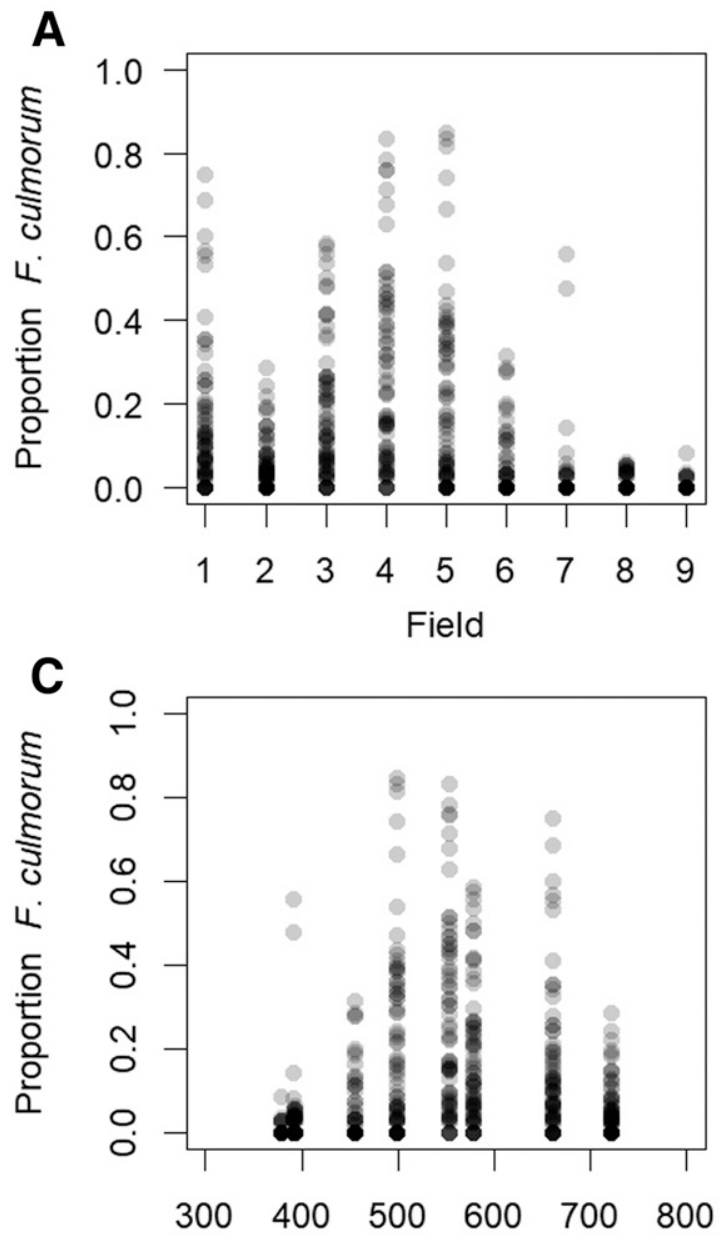

Annual precipitation $(\mathrm{mm})$

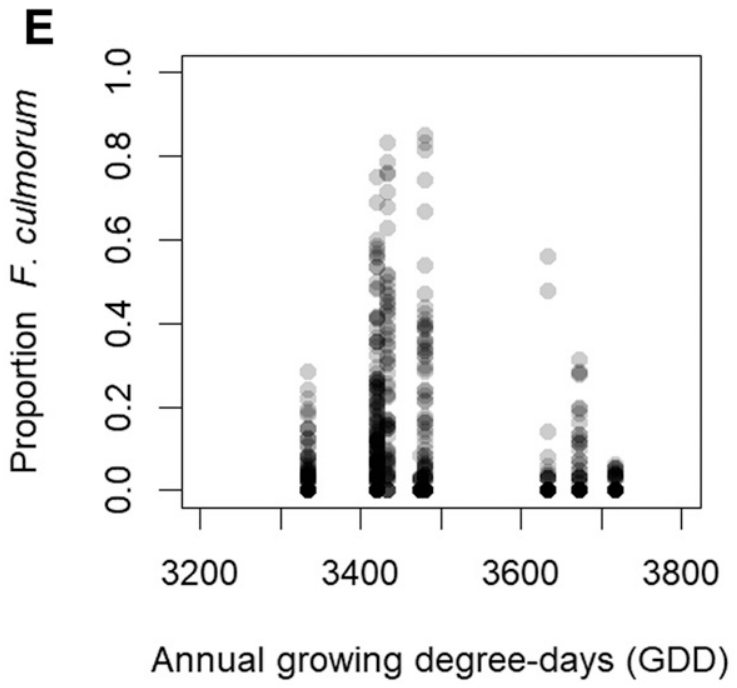

Effect of local climate on isolation frequency of F. culmorum in soil. Posterior means and 95\% HDPI of field offset parameters using equation 1 are shown in Figure 3A. These distributions are marginal, meaning that the field offsets are averaged over the other parameters. No climate data were used when calculating the field offsets shown in Figure 3. The average historic precipitation, evapotranspiration, and GDD for a sampled field are plotted against the corresponding posterior field offset in
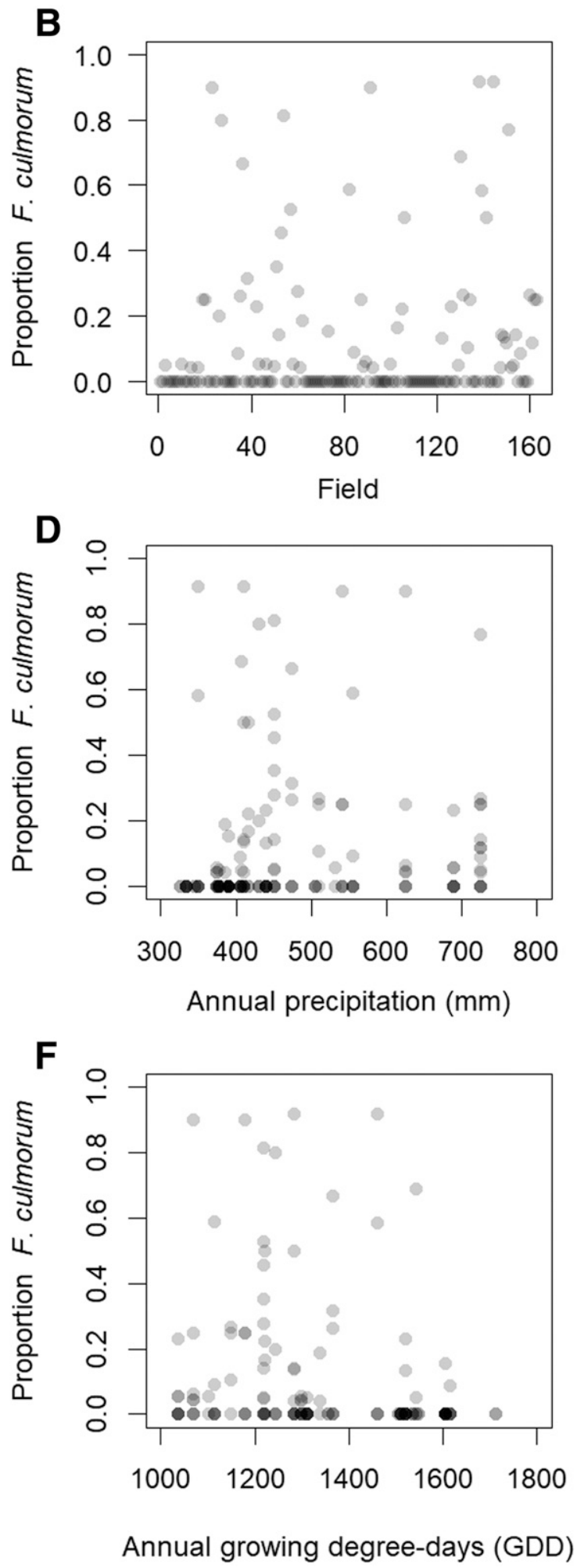

Fig. 1. Comparison of raw data collected from A, C, and E, this study and B, D, and F, Backhouse et al. (2004). Proportion of Fusarium culmorum is out of total Fusarium spp. in soil from this study and out of total Fusarium spp. in wheat from Backhouse et al. (2004). Proportions are plotted against A and B, field designation, $\mathbf{C}$ and $\mathbf{D}$, average annual precipitation (millimeters), and $\mathbf{E}$ and $\mathbf{F}$, average annual growing degree-days. 
Figure 3B to D, respectively. Fields with historically greater annual precipitation had an increased isolation frequency of F. culmorum in soil. Conversely, fields with historically greater annual evapotranspiration had a decreased isolation frequency of $F$. culmorum in soil. Fields 1 to 5 all had annual evapotranspiration below $1,150 \mathrm{~mm}$, and $96,56,98,99$, or $96 \%$ of their marginal posterior distribution was positive, respectively. Fields 6 to 9 all had annual evapotranspiration above $1,150 \mathrm{~mm}$, and $69,96,99$, or $99 \%$ of their marginal posterior distribution was negative, respectively. Annual GDD exhibited a similar trend to evapotranspiration, because both incorporate daily maximum and minimum temperature during their calculation. Simple linear relationships may be insufficient for this dataset, which can be seen with the nonlinear relationship between annual precipitation and isolation frequency in Figure 3B.

Relative elevation within a field and marginal posterior distributions of sampling quadrats. Most sampling quadrats

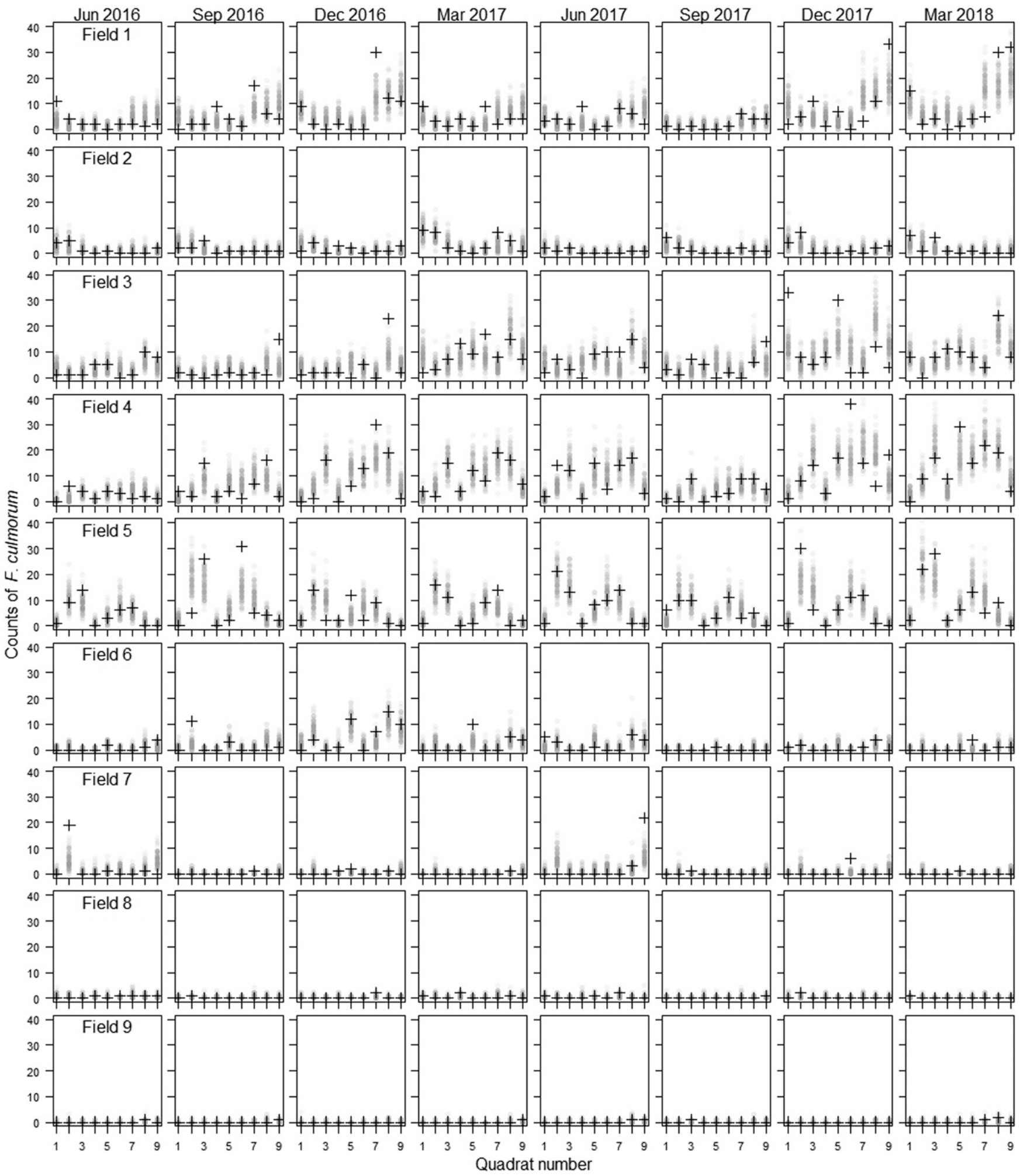

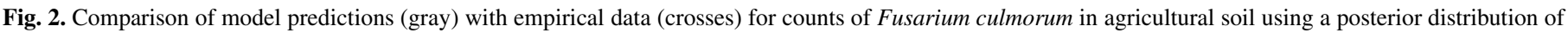

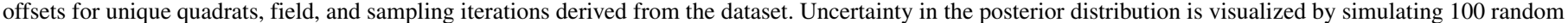
samples from the posterior distribution. 
provided no substantial increase or decrease in odds to the final observed isolation frequency of $F$. culmorum in soil. For 81 total quadrats sampled, only 26 quadrats had a marginal posterior probability distribution that was predominately positive or negative (i.e., their 95\% HDPI excluded zero). For clarity, only those quadrat offsets are shown in Supplementary Figure S3, where they are plotted against the relative elevation difference for that quadrat compared with the mean elevation for a given field. Centering of field elevations was performed, because only relative differences within a field are of interest. All quadrat offset parameters that were predominately negative occurred at quadrats that were above the average elevation for the field's sampling region. However, quadrat offsets that were predominately positive were not always from quadrats that were below average elevation for a field's sampling region. Relative elevation alone is not sufficient for explaining an increased isolation frequency of F. culmorum within a sampling quadrat. In addition, estimates of quadrat offsets can be positively skewed by a few high observed counts of F. culmorum. This can be seen in Figure 3, where high counts of F. culmorum above the predicted range increase the range of predicted values for the same quadrat in the same field across seasons.

Comparison of slope estimates. The posterior distribution of slopes after incorporating annual precipitation, evapotranspiration,
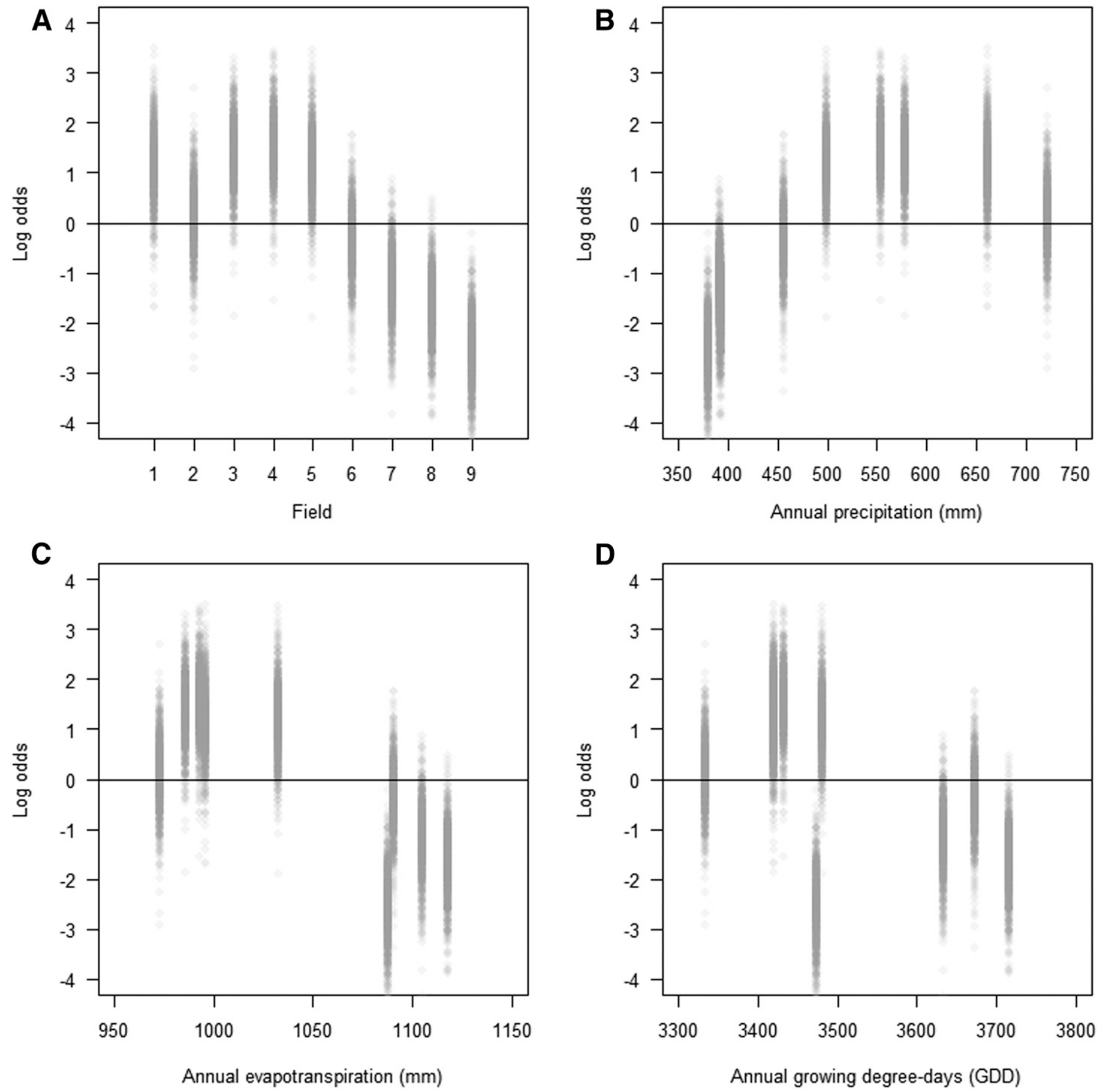

Fig. 3. Marginal posterior distributions of field offsets using only isolation frequency records of Fusarium culmorum plotted against A, field sampled, B, annual precipitation (millimeters), $\mathbf{C}$, annual grass reference evapotranspiration, and $\mathbf{D}$, annual growing degree-days (degrees Celsius per day). Climate variables are longterm historic means of 38 years from 1980 to 2018. Uncertainty in the posterior distribution is visualized by plotting 1,000 samples from the Markov chain used during approximation. 
and GDD using equations 2, 3, 4, and 5 for each field is summarized in Table 2. The same data analysis approach was also applied to previously published literature on $F$. culmorum isolation frequency in grains from eastern Australia (Backhouse et al. 2004). F. culmorum isolation frequency in soil was positively related to annual precipitation and negatively related to annual evapotranspiration, because the $95 \%$ HDPI of estimated slope parameters excluded zero when used individually in equation 2 . The distributions of slope parameters for precipitation and GDD using data from Backhouse et al. (2004) were the same sign as those of this study. However, the variability of slopes estimated using isolation frequencies of $F$. culmorum was different across datasets. The effect of annual precipitation and GDD on $F$. culmorum isolation frequency was lower in grains from eastern Australia than in soil from the INW.

The correlations between annual climate variables used in both datasets are shown in Figure 4. Annual precipitation is negatively correlated with annual GDDs across both datasets. Annual GDDs are positively correlated with annual evapotranspiration. The posterior distributions of slope parameters for specific climate variables change when combinations are used in the same equation (Table 2). In this study, the posterior distribution of the slope parameter for annual precipitation is $0.42 \pm 1.00$ when used in combination with annual evapotranspiration using equation 4 without an interaction term, meaning that there is no information gained incorporating annual precipitation after conditioning on annual evapotranspiration. A similar pattern is seen with incorporating annual GDD after conditioning on annual precipitation. The posterior distribution of slope parameters for GDD changed signs when used in combination with annual evapotranspiration using equation 4 without an interaction term. Using the dataset from Backhouse et al. (2004), the posterior distribution of slope parameters for annual precipitation changed signs when used in combination with annual GDD. Correlations between predictor variables need to be addressed before incorporation into a model equation, because the resulting coefficients may change erratically and can be potentially misleading. Posterior distributions of parameters for quadratic terms are also presented in Table 2, but there is little interpretability in their values when viewed alone. Therefore, predictions based on different model equations had to be generated for comparison.

Evaluation of model predictions. Predicted proportions of F. culmorum based on annual precipitation, evapotranspiration, or GDD using both datasets are shown in Figure 5. The effect of an annual climate variable is visualized in the trend of a line representing a simulated proportion of $F$. culmorum. The variability in proportions of $F$. culmorum owing to differences in fields, quadrats, and sampling iterations is visualized by plotting 100 simulations from the posterior distribution of each model. Predictions are highly variable independent if a singlevariable or multivariable linear or quadratic model equation is used, because the random effects of field, quadrat, and iteration remain relatively constant across all model types. Most simulated proportions of $F$. culmorum remain close to zero across the range of annual climate variables being investigated, which is seen by the dark overlapped black lines in the bottom region of the subplots in Figure 5. Simulated proportions of F. culmorum in wheat using the dataset from Backhouse et al. (2004) remain near zero regardless of the effect of annual precipitation or annual GDDs. Most of the variability in the proportion of $F$. culmorum is owing to differences in sampled fields, quadrats, and iterations, and it is not because of differences in an annual climate variable from the corresponding field of isolation.

The marginal posterior distribution of field offsets after using equation 2 with annual precipitation was centered at zero (data not shown). This represents a model equation that fits the data well, because there was no residual pattern in the field offsets that occurred when using other model equations. Improved model fit to the dataset does not guarantee that model predictions will also be improved (Fig. 5).

TABLE 2. Posterior distributions of parameters used in different multilevel model equations using different combinations of annual climate summaries ${ }^{\text {a }}$

\begin{tabular}{|c|c|c|c|c|c|c|c|c|}
\hline \multirow[b]{2}{*}{ Data source ${ }^{b}$} & \multicolumn{3}{|c|}{ Quadratic parameter } & \multicolumn{3}{|c|}{ Linear parameter } & \multirow[b]{2}{*}{ Interaction parameter } & \multirow[b]{2}{*}{ Intercept parameter ${ }^{\mathrm{d}}$} \\
\hline & $\mathrm{P}^{\mathrm{c}}$ & $\mathrm{E}^{\mathrm{c}}$ & $\mathrm{G}^{\mathrm{c}}$ & $\mathrm{P}^{\mathrm{c}}$ & $\mathrm{E}^{\mathrm{c}}$ & $\mathrm{G}^{\mathrm{c}}$ & & \\
\hline This study & & & & $1.05 \pm 0.45$ & & & & $-6.37 \pm 0.45$ \\
\hline This study & & & & & $-1.23 \pm 0.39$ & & & $-6.36 \pm 0.38$ \\
\hline This study & & & & & & $-0.82 \pm 0.53$ & & $-6.35 \pm 0.56$ \\
\hline This study & & & & $-0.42 \pm 1.00$ & $-1.64 \pm 1.00$ & & & $-6.35 \pm 0.41$ \\
\hline This study & & & & $1.15 \pm 0.76$ & $-0.17 \pm 0.73$ & & $-1.47 \pm 0.48$ & $-5.03 \pm 0.49$ \\
\hline This study & & & & $1.10 \pm 0.82$ & & $-0.05 \pm 0.80$ & & $-6.35 \pm 0.51$ \\
\hline This study & & & & $2.38 \pm 0.83$ & & $1.10 \pm 0.76$ & $1.39 \pm 0.61$ & $-5.28 \pm 0.60$ \\
\hline This study & & & & & $-2.68 \pm 0.68$ & $1.60 \pm 0.68$ & & $-6.38 \pm 0.28$ \\
\hline This study & & & & & $-3.19 \pm 0.51$ & $2.31 \pm 0.53$ & $-0.84 \pm 0.30$ & $-5.61 \pm 0.32$ \\
\hline This study & $-1.22 \pm 0.20$ & & & $-1.56 \pm 0.20$ & & & & $-5.17 \pm 0.26$ \\
\hline This study & & $-1.15 \pm 0.37$ & & & $-0.75 \pm 0.67$ & & & $-5.62 \pm 0.75$ \\
\hline This study & & & $-0.25 \pm 0.72$ & & & $-0.70 \pm 0.65$ & & $-6.10 \pm 0.91$ \\
\hline This study & $-3.39 \pm 2.94$ & $-1.93 \pm 2.60$ & & $1.41 \pm 0.77$ & $-0.33 \pm 0.72$ & & $-4.27 \pm 5.58$ & $-4.97 \pm 0.61$ \\
\hline This study & $-1.62 \pm 0.45$ & & $-0.92 \pm 0.68$ & $1.28 \pm 0.53$ & & $-0.02 \pm 0.62$ & $-1.35 \pm 0.90$ & $-4.92 \pm 0.39$ \\
\hline This study & & $-1.49 \pm 1.12$ & $-1.32 \pm 1.05$ & & $-2.33 \pm 0.78$ & $1.55 \pm 0.75$ & $-1.81 \pm 1.83$ & $-5.21 \pm 0.48$ \\
\hline Backhouse et al. (2004) & & & & $0.59 \pm 0.21$ & & & & $-6.25 \pm 0.29$ \\
\hline Backhouse et al. (2004) & & & & & & $-0.89 \pm 023$ & & $-6.28 \pm 0.29$ \\
\hline Backhouse et al. (2004) & & & & $-0.47 \pm 0.38$ & & $-1.33 \pm 0.43$ & & $-6.31 \pm 0.29$ \\
\hline Backhouse et al. (2004) & & & & $0.29 \pm 0.52$ & & $-1.09 \pm 0.42$ & $0.60 \pm 0.29$ & $-5.86 \pm 0.34$ \\
\hline Backhouse et al. (2004) & $-0.60 \pm 0.24$ & & & $1.26 \pm 0.36$ & & & & $-5.68 \pm 0.33$ \\
\hline Backhouse et al. (2004) & & & $-0.45 \pm 0.21$ & & & $-1.07 \pm 0.25$ & & $-5.88 \pm 0.32$ \\
\hline Backhouse et al. (2004) & $-2.18 \pm 0.98$ & & $-1.41 \pm 1.00$ & $0.01 \pm 0.62$ & & $-1.26 \pm 0.61$ & $-3.09 \pm 1.82$ & $-5.31 \pm 0.48$ \\
\hline
\end{tabular}

a Values are presented as mean \pm standard deviation.

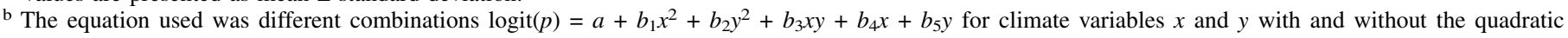
parameters or interaction parameters, where $p$ is the proportion of Fusarium culmorum. Climate variables were also tested individually. Parameters for each unique observation within a given cluster of the dataset (fields, iterations, and quadrats) were included in the equation as offsets from $a$, but they are not shown.

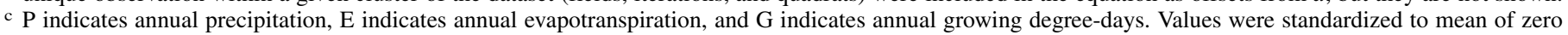
and standard deviation of one before model fitting.

$\mathrm{d}$ The intercept $a$ is the population parameter and the hierarchical term in the multilevel model. 


\section{DISCUSSION}

This study provides an example of utilizing a multilevel modeling approach to study variability of counts for a fungal plant pathogen in soil based on sampling quadrat, field, and iteration. This approach provided information suggesting that most of the observed variability is owing to the field being sampled from. Investigation into variability within sampling quadrats showed lower frequencies of isolation from higher elevations within a given field. To further test if differences in isolation frequency of $F$. culmorum in a field could be attributed to local climate, different combinations of effect parameters were incorporated into the model equation.

Probability distributions for highly variable counts of fungal plant pathogens in soil have classically been assigned to the negative binomial (Dillard and Grogan 1985; Hau et al. 1982; Punja et al. 1985; Stanghellini et al. 1982; Taylor et al. 1981). This approach accounts for overdispersion in the data by utilizing a conceptual construct that extends the Poisson count distribution such that the Poisson rate parameter follows a gamma distribution (McElreath 2016). Although this formulation accounts for unobserved variability in fungal counts, it does not give much more information apart from confirming that the population of a fungal plant pathogen is spatially aggregated in soil. The data analysis approach in this study accounted for overdispersion by allowing unique clusters within the dataset to vary independently. Differences in unique cluster parameters derived from the dataset were used to make inferences on possible sources of variability.

Of 81 unique acre quadrats sampled, the marginal posterior distribution of only eight were predominately negative with a 95\% HDPI that excluded zero. All of those quadrats were from higher relative elevations within the sampling region for a given field. The landscape of the INW is known for its hilly topography, and it has been known for a long time that agricultural practices, such as tilling, have made the high points within fields of the INW drier and less productive for plant growth, which negatively impacts wheat yields (Rockie 1951; Yang et al. 1998). Precipitation occurs primarily during the winter months when cropland is seeded to winter wheat and provides only minimal cover until spring (Frazier et al. 1983). It follows that isolation frequency of F. culmorum in soil is decreased in the eroded high points of fields across the INW. There have been observed cases of FRR caused by F. culmorum in the INW, where the pathogen

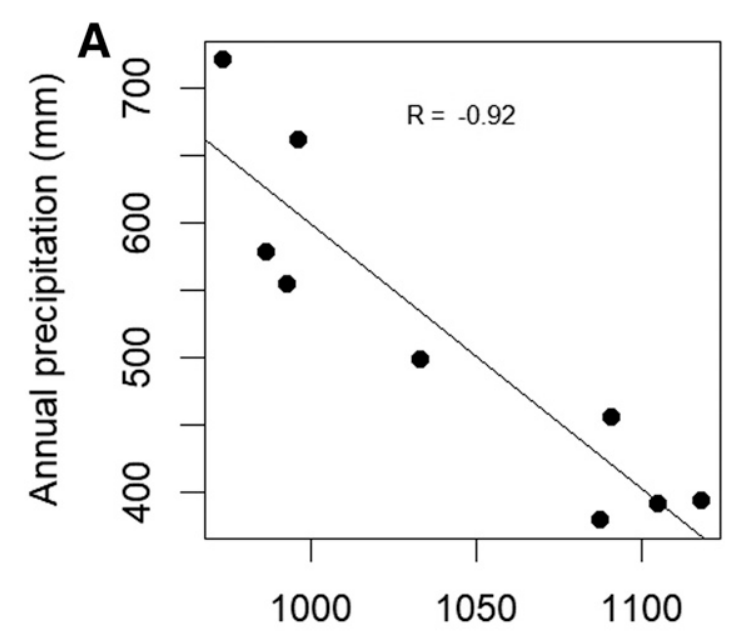

Annual evapotranspiration $(\mathrm{mm})$

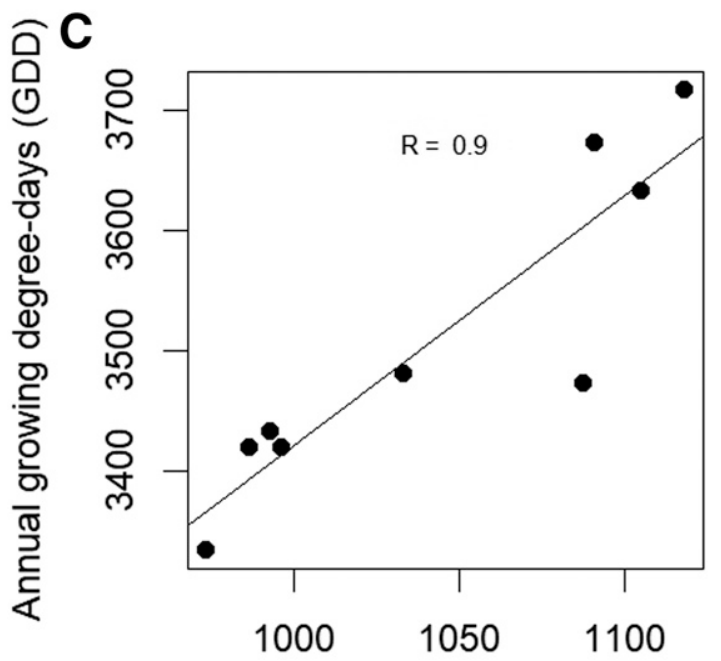

Annual evapotranspiration ( $\mathrm{mm}$ )
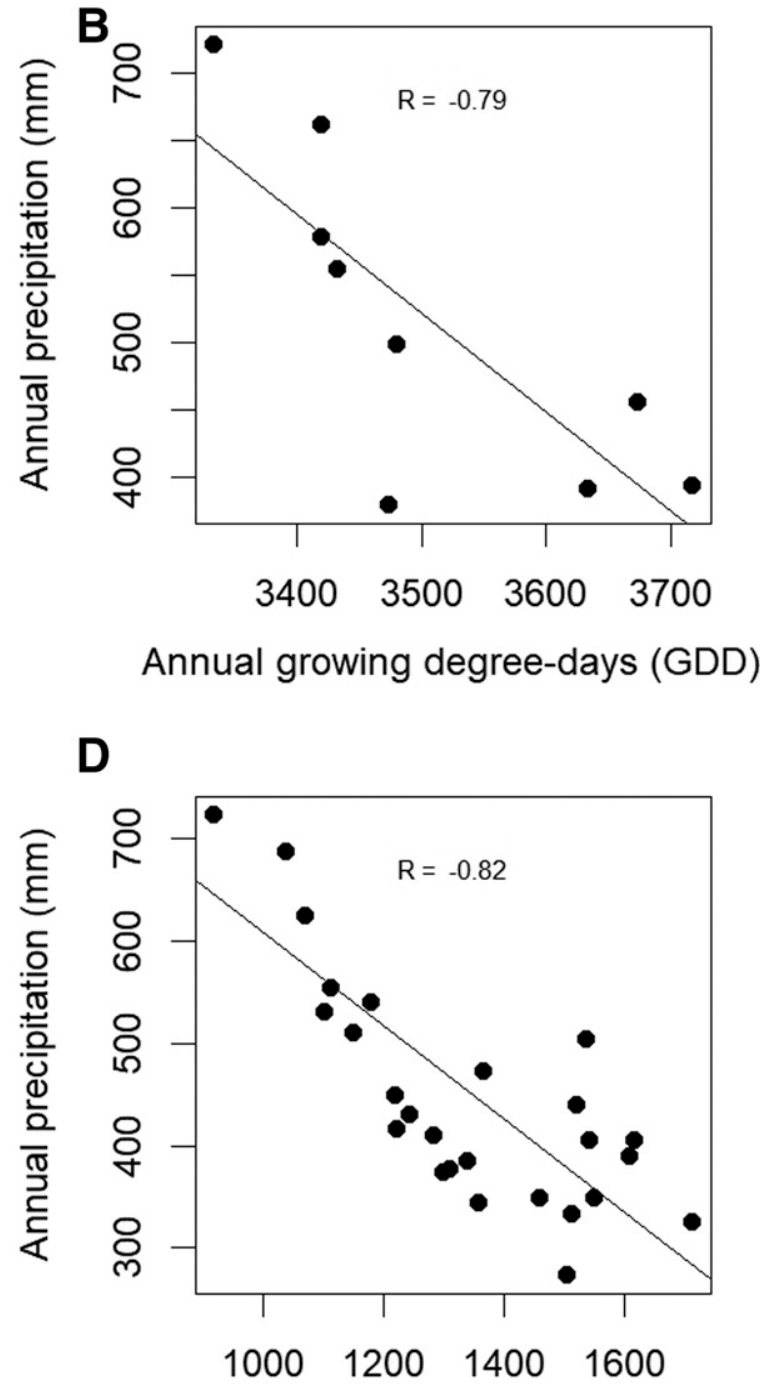

Annual growing degree-days (GDD)

Fig. 4. Correlations between predictor variables in the dataset from A to C, this study or D, Backhouse et al. (2004). The correlations are A, between annual evapotranspiration and annual precipitation, B, between annual growing degree-days and annual precipitation, $\mathbf{C}$, between annual evapotranspiration and annual growing degree-days, and $\mathbf{D}$, between annual growing degree-days and annual precipitation. The Pearson correlation coefficient between two predictor variables is denoted using R. 
density was highest halfway along a slope but undetectable at the hilltop (Cook 1980). Lower soil moisture within high points of a field may have accounted for a marginal decrease in isolation frequency when accounting for relative elevation. However, differences in fields accounted for more of the variability in isolation frequency of $F$. culmorum compared with differences in sampling quadrats, because the posterior distribution of $\sigma$ was greater for the field parameter compared with the quadrat parameter using equation 1 .

Isolation frequencies of $F$. culmorum within a field fluctuated seasonally as well, but the differences were not consistent across fields. In general, the isolation frequency of F. culmorum in the soil of
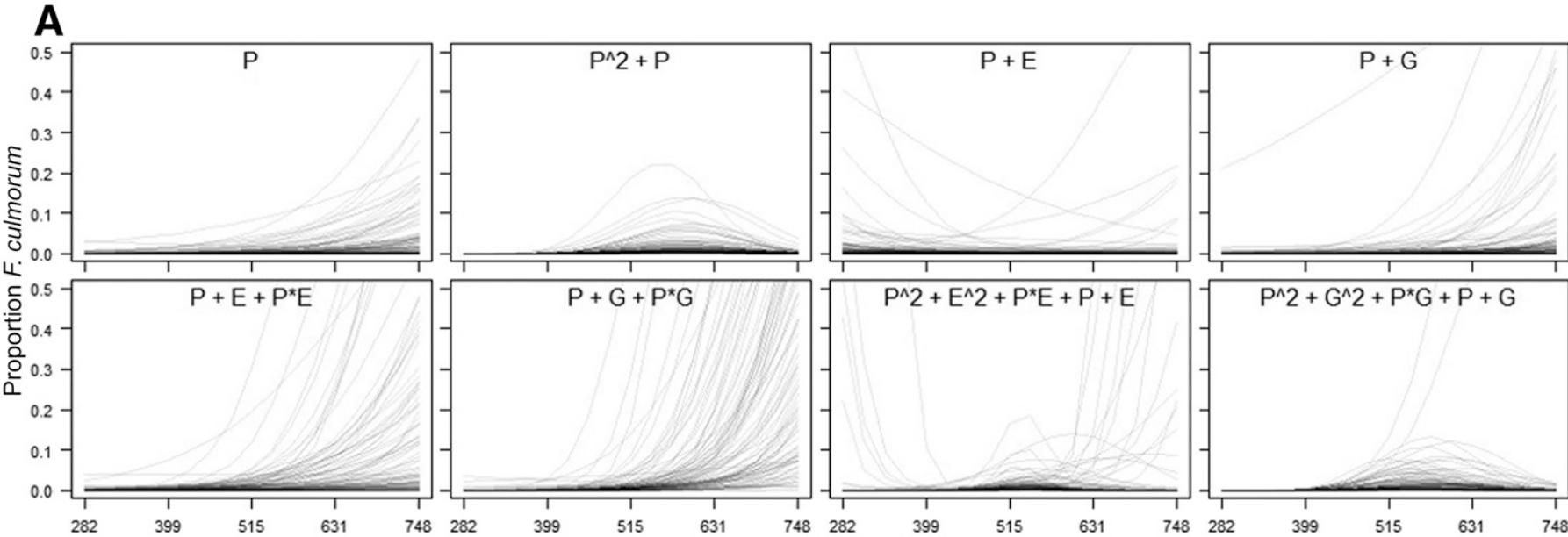

B
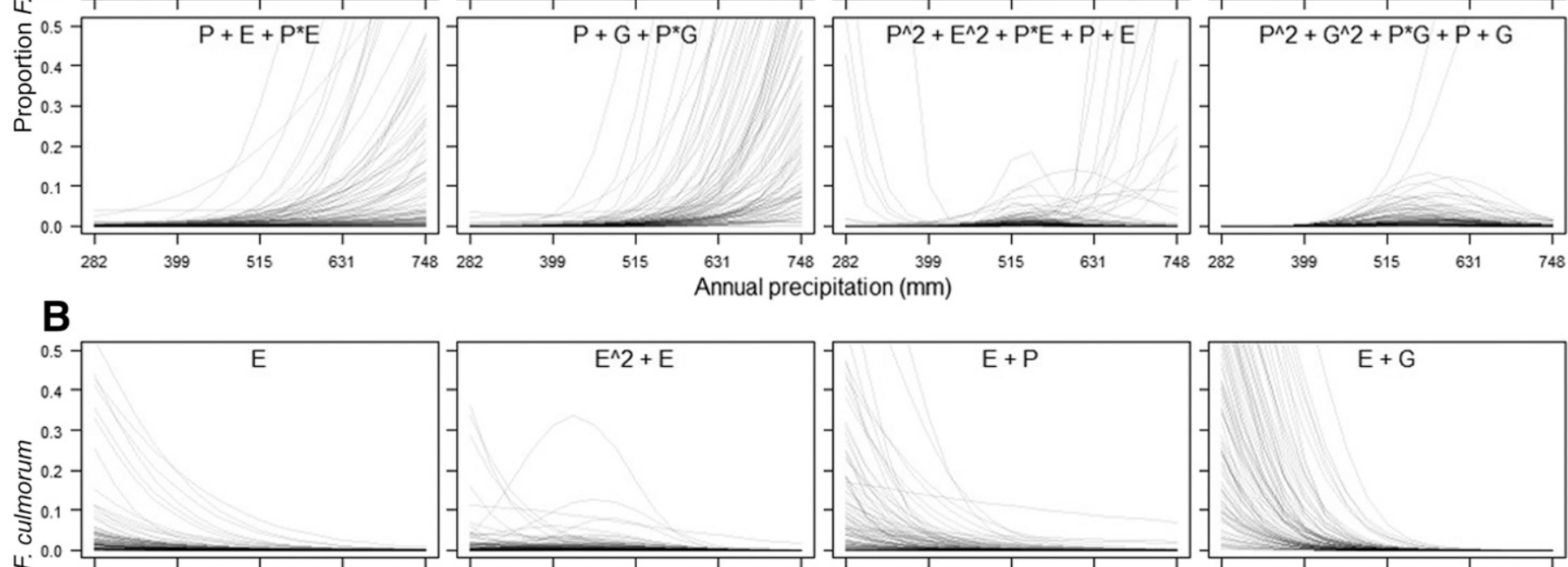

Annual precipitation ( $\mathrm{mm}$ )
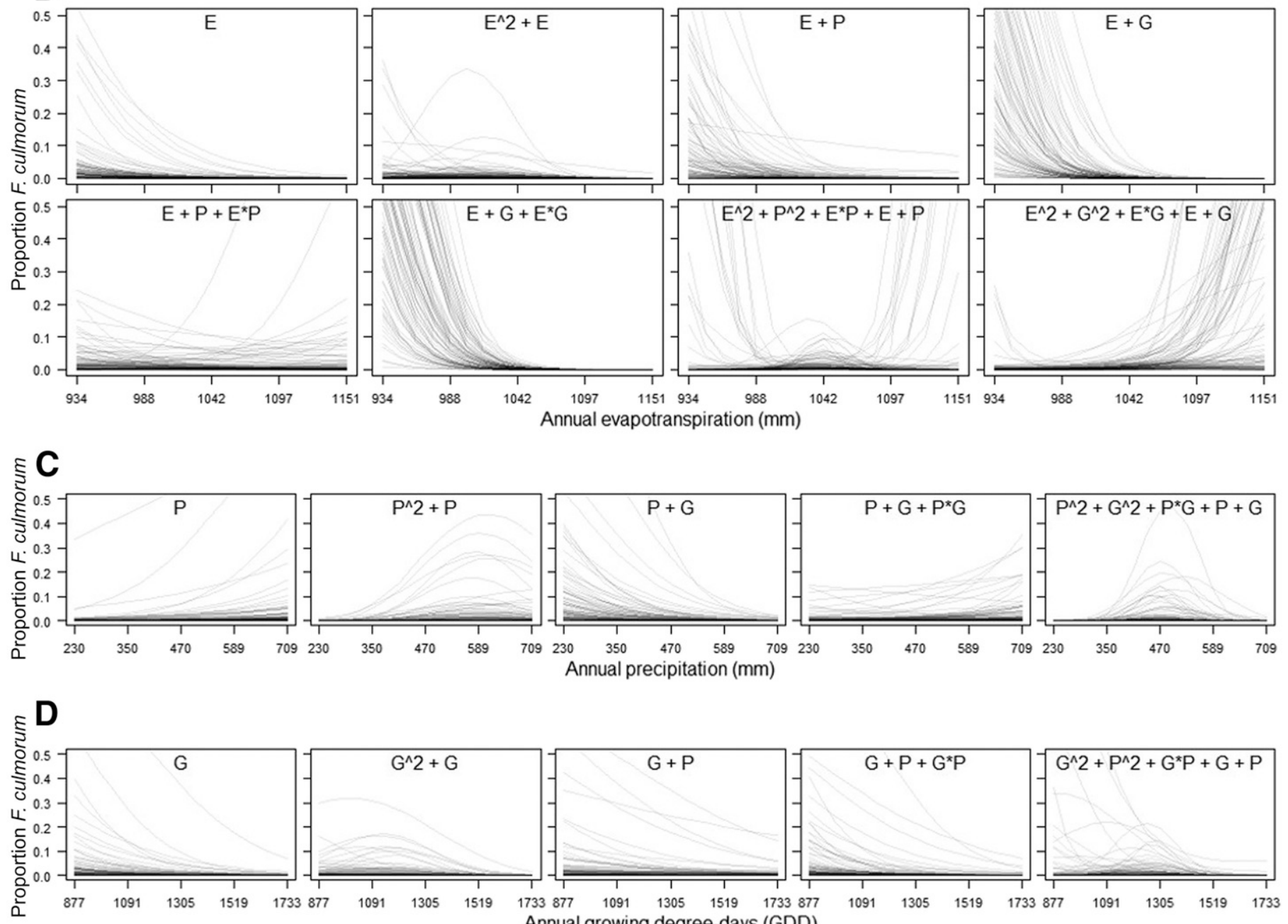

Fig. 5. Predicted proportions of Fusarium culmorum of total Fusarium spp. in soil based on A, annual precipitation or B, annual evapotranspiration and predicted proportions of $F$. culmorum of total Fusarium spp. in wheat based on $\mathbf{C}$, annual precipitation or $\mathbf{D}$, annual growing degree-days using the dataset from Backhouse et al. (2004). Variables used were annual precipitation (P), annual evapotranspiration (E), and annual growing degree-days (G). Letters in each subplot indicate which climate variables were used in the model equation, and`2 and * denote quadratic or interaction parameter, respectively. Each line represents the impact of the climate variable by simulating a new proportion of F. culmorum using the posterior distribution of each multilevel model. Variation among sampled fields, quadrats, and iterations is visualized by plotting 100 simulated proportions of $F$. culmorum. 
an agricultural field was highest in the winter and spring and lowest in the fall. Previous monthly observations of $F$. culmorum population densities in wheat field soils of the United Kingdom also fluctuated differently according to the field sampled, but multiple increases in F. culmorum population densities were observed during the spring after rainfall events (Bateman and Murray 2001). To account for differences in how isolation frequency changed across fields over the same season, all sampling points were treated as random, representing a conservative choice. Models that combine the results from fields together using the same temporal sequence or season can also be evaluated. A marginal decrease in isolation frequency in the fall can still be observed when using temporal sequence or season.

After averaging over the uncertainty in both sampling quadrat and iteration, the marginal posterior distributions for field offsets still showed differences. Plotting the field offset against historical averages for annual precipitation and evapotranspiration showed positive and negative relationships, respectively, with isolation frequency of F. culmorum (Fig. 4). This relationship was further investigated by adding a slope term into the varying intercepts model using equation 2, and the posterior distributions were predominately positive and negative for annual precipitation and evapotranspiration, respectively (Table 2 ). The slope term investigates the ability of a single climate variable to predict the isolation frequency of $F$. culmorum assuming that there is a proportional relationship between the two. The same modeling approach was applied to a dataset containing 163 fields with isolation frequency of F. culmorum in grains, annual precipitation, and annual GDD. The slopes were predominately the same sign as those of this study, although the magnitudes of the slope parameters were less when using the dataset from Backhouse et al. (2004).

Isolation frequency of $F$. culmorum in soil was typically higher in fields within the INW with greater annual precipitation and lower evapotranspiration. This is in agreement with an earlier survey of wheat stubble from the region, where the researchers showed that F. culmorum was isolated more frequently from cooler and wetter locations and negatively correlated with temperature parameters (Poole et al. 2013). Prevalence of F. culmorum of total Fusarium spp. in wheat tissues was higher in the INW after a wet winter and spring compared with after a dry summer and autumn (Smiley and Patterson 1996).

F. culmorum has a cosmopolitan distribution in soil (Nelson et al. 1983; Samson et al. 2004), but it is most commonly found in temperate regions (Leslie and Summerell 2008) However, surveys of grains have shown that F. culmorum is not found in areas with high summer temperatures and low rainfall in Australia and the INW (Backhouse and Burgess 2002; Poole et al. 2013). Comparison of the two datasets suggests that the effect of rainfall on the distribution of $F$. culmorum is more variable in plant tissues as opposed to soil samples. Although F. culmorum can be considered cosmopolitan in soil and was frequently isolated from the INW, isolation of F. culmorum from plant tissues is a rarer event that is dependent on conditions for successful colonization.

Although all slope parameters for a given variable were predominantly the same sign, their variability is too large to provide useful predictions for growers even after increasing complexity with multivariable models and polynomial terms (Fig. $5)$. The annual summary of a climate variable combined with sampling only once a year may be too coarse of a resolution to adequately address how distributions of plant pathogens may shift under climate change. Correlations between predictor variables need to be considered when constructing additive model equations, because annual climate variables were highly correlated in both the INW and eastern Australia (Fig. 4). The posterior distributions of slope parameters can potentially change signs when used in combination, which arises from multicollinearity (Table 2). However, the results from using combinations of climate variables suggest that temperature-related variables, such as annual evapotranspiration, may have greater predictive power than annual precipitation. Polynomial regression using annual precipitation reduced the posterior distribution of field offsets compared with linear regression, and the predicted range of $F$. culmorum proportions was also lower compared with linear regression. These results suggest that there is only a slight relationship between annual precipitation and isolation frequency of $F$. culmorum in soil. Annual evapotranspiration showed greater predictive power than annual precipitation when the two variables were used in combination (Table 2). The predicted range of $F$. culmorum in wheat in eastern Australia also did not increase under higher annual precipitation or lower annual GDD (Fig. 5C and D). There is substantial variability in the proportion of $F$. culmorum in soil or wheat owing to differences in fields, quadrats, and sampling iterations, which are not explained by an annual summary of a climate variable, such as precipitation or GDDs. The original dataset is quite variable, and no clear trend was initially seen when plotting the raw data versus an annual climate variable (Fig. 1). This uncertainty is carried forward into the model predictions and visualized by simulating new varying intercepts, which incorporate the random effects owing to differences in sampled fields, quadrats, and iterations. Models that fit the dataset well, such as equation 2 with annual precipitation, still produce predictions with considerable uncertainty.

Fungal proportion data provide information about the relative incidence of a plant pathogen of interest referenced against the total amount of fungi within a particular fungal genus, which allows researchers to address ecological questions while accounting for species diversity. It is difficult to report these proportions to growers in a clear and interpretable way. In general, higher proportions of F. culmorum could lead to increased disease incidence and yield losses (Cook 1968; Hollaway et al. 2013). It is likely that growers would require additional information to provide context for fungal proportion data. Reporting proportions out of the number of wheat plants sampled can be adapted to provide field estimates of the risk associated with a particular plant pathogen. Incorporating the soil dilution factor could provide an estimate of population density, which could be interpreted in a similar manner with seeding density for a field. However, the population density estimates are based on highly variable fungal counts, and new methods of summarizing the variability within a field are needed.

The tools and methodologies provided in this study should facilitate a more comprehensive analysis of the effect of local climate on the distribution of F. culmorum across the INW now that differences in experimental clusters have been investigated. Predictive values of climate variables from climate change ensemble datasets can be used as inputs to generate predicted ranges of plant pathogen proportions. Model output provides a framework for inferences that can lead to managerial decisions for future cropping practices under climate change tailored to the relevant data being conditioned on to minimize yield losses and limit mycotoxin contamination of grains.

\section{LITERATURE CITED}

Abatzoglou, J. T. 2013. Development of gridded surface meteorological data for ecological applications and modelling. Int. J. Climatol. 33:121-131.

ASCE-EWRI. 2005. The ASCE Standardized Reference Evapotranspiration Equation. ASCE-EWRI Standardization of Reference Evapotranspiration Task Committee Report. American Society of Civil Engineers, Reston, VA.

Backhouse, D., Abubakar, A. A., Burgess, L. W., Dennisc, J. I., Hollaway, G. J., Wildermuth, G. B., and Henry, F. J. 2004. Survey of Fusarium species associated with crown rot of wheat and barley in eastern Australia. Australas. Plant Pathol. 33:255-261.

Backhouse, D., and Burgess, L. W. 2002. Climatic analysis of the distribution of Fusarium graminearum, F. pseudograminearum and F. culmorum on cereals in Australia. Australas. Plant Pathol. 31:321-327.

Bakan, B., Giraud-Delville, C., Pinson, L., Richard-Molard, D., Fournier, E., and Brygoo, Y. 2002. Identification by PCR of Fusarium culmorum strains producing large and small amounts of deoxynivalenol. Appl. Environ. Microbiol. 68:5472-5479.

Bateman, G. L., and Murray, G. 2001. Seasonal variations in populations of Fusarium species in wheat-field soil. Appl. Soil Ecol. 18:117-128. 
Betancourt, M. 2017. A conceptual introduction to Hamiltonian Monte Carlo. arXiv:1701.02434.

Beyer, M., Verreet, J. A., and Ragab, W. S. 2005. Effect of relative humidity on germination of ascospores and macroconidia of Gibberella zeae and deoxynivalenol production. Int. J. Food Microbiol. 98:233-240.

Bianchini, A., Horsley, R., Jack, M. M., Kobielush, B., Ryu, D., Tittlemier, S., Wilson, W. W., Abbas, H. K., Abel, S., Harrison, G., and Miller, J. D. 2015. DON occurrence in grains: A North American perspective. Cereal Foods World 60:32-56.

Carpenter, B., Gelman, A., Hoffman, M. D., Lee, D., Goodrich, B., Betancourt, M., Brubaker, M., Guo, J., Li, P., and Riddell, A. 2017. Stan: A probabilistic programming language. J. Stat. Softw. 76:1-32.

Cook, R. J. 1968. Fusarium root and foot rot of cereals in Pacific Northwest. Phytopathology 58:127-131.

Cook, R. J. 1980. Fusarium foot rot of wheat and its control in the Pacific Northwest. Plant Dis. 64:1061-1066.

Cook, R. J., and Bruehl, G. W. 1968. Relative significance of pasrasitism versus saprophytism in colonization of wheat straw by Fusarium roseum culmorum in field. Phytopathology 58:306-308.

Cowger, C., Patton-Özkurt, J., Brown-Guedira, G., and Perugini, L. 2009. Post-anthesis moisture increased Fusarium head blight and deoxynivalenol levels in North Carolina winter wheat. Phytopathology 99: 320-327.

De Wolf, E, Madden, L., and Lipps, P. 2003. Risk assessment models for wheat Fusarium head blight epidemics based on within-season weather data. Phytopathology 93:428-435.

Dillard, H. R., and Grogan, R. G. 1985. Relationship between sclerotial spatial pattern and density of Sclerotinia minor. Phytopathology 75:90-94.

Dill-Macky, R., and Jones, R. K. 2000. The effect of previous crop residues and tillage on Fusarium head blight of wheat. Plant Dis. 84:71-76.

Douglas, C. L., Jr., Rickman, R. W., Klepper, B. L., and Zuzel, J. F. 1992. Agroclimatic zones for dryland winter wheat producing areas of Idaho, Washington, and Oregon. Northwest Sci. 66:26-34

Franzen, D. W., and Cihacek, L. J. 1998. Soil sampling as a basis for fertilizer application. NDSU Extension Service Publication SF-990. North Dakota State University, Fargo, ND

Frazier, B. E., McCool, D. K., and Engle, C. F. 1983. Soil erosion in the Palouse: An aerial perspective. J. Soil Water Conserv. 38:70-74

Gang, G., Miedaner, T., Schuhmacher, U., Schollenberger, M., and Geiger, H. H. 1998. Deoxynivalenol and nivalenol production by Fusarium culmorum isolates differing in aggressiveness toward winter rye. Phytopathology 88:879-884.

Gelman, A. 2006. Prior distributions for variance parameters in hierarchical models. Bayesian Anal. 1:515-534.

Gelman, A., and Rubin, D. 1992. Inference from iterative simulation using multiple sequences. Stat. Sci. 7:457-511.

Hau, F. C., Campbell, C., and Beute, M. K. 1982. Inoculum distribution and sampling methods for Cylindrocladium crotalariae. Plant Dis. 66:568-571.

Hollaway, G. J., Evans, M. L., Wallwork, H., Dyson, C. B., and McKay, A. C. 2013. Yield loss in cereals, caused by Fusarium culmorum and F. pseudograminearum, is related to fungal DNA in soil prior to planting, rainfall, and cereal type. Plant Dis. 97:977-982.

Hu, Q., Weiss, A., Feng, S., and Baenziger, P. S. 2005. Earlier winter wheat heading dates and warmer spring in the US Great Plains. Agric. For. Meteorol. 135:284-290.

Inglis, D. A., and Cook, R. J. 1986. Persistence of chlamydospores of Fusarium culmorum in wheat field soils of eastern Washington. Phytopathology 76:1205-1208

Jennings, P., Coates, M. E., Turner, J. A., Chandler, E. A., and Nicholson, P. 2004. Determination of deoxynivalenol and nivalenol chemotypes of Fusarium culmorum isolates from England and Wales by PCR assay. Plant Pathol. 53:182-190.

Lacey, J., Bateman, G., and Mirocha, J. 1999. Effects of infection time and moisture on development of ear blight and deoxynivalenol production by Fusarium spp. in wheat. Ann. Appl. Biol. 134:277-283.

Laraba, I., Boureghda, H., Abdallah, N., Bouaicha, O., Obanor, F., Moretti, A., Geiser, D., Kim, H., McCormic, S., Proctor, R., Kelly, A., Ward, T., and O'Donnel, K. 2017. Population genetic structure and mycotoxin potential of the wheat crown rot and head blight pathogen Fusarium culmorum in Algeria. Fungal Genet. Biol. 103:34-41.

Leslie, J. F., and Summerell, B. A. 2008. The Fusarium Laboratory Manual. Blackwell Publishing Ltd, Ames, IA.

Lukas, S., Abbas, S. J., Karlovsky, P., Potthoff, M., and Joergensen, R. G. 2014. Substrate use and survival of fungal plant pathogens on maize residues at winter temperatures around freezing point. Soil Biol. Biochem. 77:141-149.

McElreath, R. 2016. Statistical Rethinking: A Bayesian Course with Examples in R and Stan. CRC Press Taylor \& Francis Group, Boca Raton, FL.

McMaster, G. S., and Wilhelm, W. W. 1997. Growing degree-days: One equation, two interpretations. Agric. For. Meteorol. 87:291-300.
Nash, S. M., and Snyder, W. C. 1962. Quantitative estimations by plate counts of propagules of the bean root rot Fusarium in field soils. Phytopathology 52:567-572.

Nelson, P. E., Toussoun, T. A., and Marasas, W. F. O. 1983. Fusarium Species: An Illustrated Manual for Identification. PSU Press, State College, PA.

Pan, B., Schillinger, W., Young, F., Kirby, E., Yorgey, G., Borelli, K., Brooks, E., McCracken, V., Maaz, T., Machado, S., Madsen, I., Johnson-Maynard, J., Port, L., Painter, K., Huggins, D., Esser, A., Collins, H., Stockle, C., and Eigenbrode, S. 2017. Integrating historic agronomic and policy lessons with new technologies to drive farmer decisions for farm and climate: The case of Inland Pacific Northwestern U.S. Front. Environ. Sci. 5:76.

Papendick, R. I., and Cook, R. J. 1974. Plant water stress and development of Fusarium foot rot in wheat subjected to different cultural practices. Phytopathology 64:358-363.

Paulitz, T., Smiley, R., and Cook, R. J. 2002. Insights into the prevalence and management of soilborne cereal pathogens under direct seeding in the Pacific Northwest, U.S.A. Can. J. Plant Pathol. 24:416-428.

Poole, G. J., Smiley, R. W., Walker, C., Huggins, D., Rupp, R., Abatzoglou, J., Garland-Campbell, K., and Paulitz, T. C. 2013. Effect of climate on the distribution of Fusarium spp. causing crown rot of wheat in the Pacific Northwest of the United States. Phytopathology 103:1130-1140.

Punja, Z. K., Smith, V. L., Campbell, C. L., and Jenkins, S. F. 1985. Sampling and extraction procedures to estimate numbers, spatial pattern, and temporal distribution of sclerotia of Sclerotium rolfsii in soil. Plant Dis. 69: 469-474.

Quarta, A., Mita, G., Haidukowski, M., Santino, A., Mule, G., and Visconti, A. 2005. Assessment of trichothecene chemotypes of Fusarium culmorum occurring in Europe. Food Addit. Contam. 22:309-315.

Rockie, W. A. 1951. Snowdrift erosion in the Palouse. Geogr. Rev. 41: 457-463.

Rodriguez-Molina, M. C., Tello-Marquina, J. C., Torres-Vila, L. M., and Bielza-Lino, P. 2000. Micro-scale systematic sampling of soil: Heterogeneity in populations of Fusarium oxysporum, F. solani, F. roseum and F. moniliforme. J. Phytopathol. 148:609-614.

Samson, R. A., Hoekstra, E. S., and Frisvad, J. C. 2004. Introduction to Food- and Airborne Fungi (No. Ed. 7). Centraalbureau voor Schimmelcultures (CBS). Ponsen \& Looyen, Wageningen, The Netherlands

Sangalang, A. E., Burgess, L. W., Backhouse, D., Duff, J., and Wurst, M. 1995. Mycogeography of Fusarium species in soils from tropical, arid and Mediterranean regions of Australia. Mycol. Res. 99:523-528.

Schillinger, W. F., Papendick, R. I., and McCool, D. K. 2010. Soil and water challenges for Pacific Northwest agriculture. Pages 47-80 in: Soil and Water Conservation Advances in the United States, Special Publication 60. T. M. Zobeck and W. F. Schillinger, eds. Soil Science Society of America, Madison, WI.

Sitton, J. W., and Cook, R. J. 1981. Comparative morphology and survival of chlamydospores of. Fusarium roseum "Culmorum" and "Graminearum." Phytopathology 71:85-90.

Smiley, R. W., and Patterson, L. M. 1996. Pathogenic fungi associated with Fusarium foot rot of winter wheat in the semiarid Pacific Northwest. Plant Dis. 80:944-949.

Snijders, C. H. A., and Perkowski, J. 1990. Effects of head blight caused by Fusarium culmorum on toxin content and weight of wheat kernels. Phytopathology 80:566-570.

Stanghellini, M. E., Von Bretzel, P., Kronland, W. C., and Jenkins, A. D. 1982. Inoculum densities of Pythium aphanidermatum in soils of irrigated sugar beet fields in Arizona. Phytopathology 72:1481-1485.

Strausbaugh, C. A., Bradley, C. A., Koehn, A. C., and Forster, R. L. 2004. Survey of root diseases of wheat and barley in southeastern Idaho. Can. J. Plant Pathol. 26:167-176.

Taylor, J. D., Griffin, G. J., and Garren, K. H. 1981. Inoculum pattern, inoculum density-disease incidence relationships, and population fluctuations of Cylindrocladium crotalariae microsclerotia in peanut field soil. Phytopathology 71:1297-1302.

Windels, C., Burnes, P., and Kommedahl, T. 1993. Fusarium species stored on silica gel and soil for ten years. Mycologia 85:21-23.

Xu, X. M., Monger, W., Ritieni, A., and Nicholson, P. 2007. Effect of temperature and duration of wetness during initial infection periods on disease development, fungal biomass and mycotoxin concentrations on wheat inoculated with single, or combinations of, Fusarium species. Plant Pathol. 56:943-956.

Yang, C., Peterson, C. L., Shropshire, G. J., and Otawa, T. 1998. Spatial variability of field topography and wheat yield in the Palouse region of the Pacific Northwest. Trans. ASAE 41:17-27.

Yekkour, A., Toumatia, O., Meklat, A., Verheecke, C., Sabaou, N., Zitouni, A., and Mathieu, F. 2015. Deoxynivalenol-producing ability of Fusarium culmorum strains and their impact on infecting barley in Algeria. World J. Microbiol. Biotechnol. 31:875-881. 